\title{
酢酸セルロース誘導体逆浸透膜による低分子量有機物 水溶液の分離特性の研究
}

\author{
黄継才・大矢晴彦・根岸洋一
}

横浜国立大学工学部物質工学科 $\quad 240$ 横浜市保土ヶ谷区常磐台 156

\section{Studies on Reverse Osmosis Separation of Aqueous Solutions of Low Molecular Weight Organics by Cellulose Acetate Derivative Membranes}

\author{
Huang Jicai*, Haruhiko Ohya, Yoichi Negishi \\ Department of Material Science and Chemical Engineering, Faculty of Engineering, \\ Yokohama National University, Hodogayaku, Yokohama 240, Japan \\ *On leave from Guangzhou Institute of Chemistry, Academia Sinica, China
}

\begin{abstract}
Membranes of cellulose acetate derivatives-cyanoethyl cellulose acetate (CACN), hydroxypropyl cellulose acetate (CAHP) and cellulose acetate (CA) have been prepared. The reverse osmosis separation of aliphatic acids, alcohols and amines have been made. It was found that for $n$-alkyl organics, the solute rejections $(\mathrm{Ra})$ firstly increased with the increase of carbon numbers of $n$-alkyl organics and reached a maximum when the organic molecule contained about three carbon atoms, and then decreased or kept stable. The order of solute rejections for organics with different structures was $n-<$ iso- sec-<tert- because of the steric hindrance. The effect of oprating pressure on the properties of reverse osmosis have also been investigated and it was found that the solute rejections and the fluxes of solution increased with the increas of the operating pressure in the experimental extent. An analysis of experimental data with Spiegler-Kedem's transport model has been carried out and the membrane constants such as reflection coefficient $\sigma$, solute and hydraulic permeabilities $\omega$ and Lp for several organic solutes have been obtained.
\end{abstract}

Key words : Reverse osmosis, Low molecular weight organics, Cellulose acetate, Cyanoethyl cellulose acetate, Hydroxypropyl cellulose acetate

\section{INTRODUCTION}

Reverse osmosis separation of organic solutes in aqueous solution are of interest from the point of view of both the mechanism of the process as well as its application for wast water treatment and water pollution control. Matsuura and Sourirajan ${ }^{1)} \sim 5$ ) used the porous cellulose acetate membranes to study such separations with respect to alcohols, phenols, organic acids, hydrocarbons, 
Table 1 Membrane Characteristics

\begin{tabular}{lcccc}
\hline membrane & $\begin{array}{c}\text { before testing with organics } \\
\text { salt rejection } \\
(\%)\end{array}$ & $\begin{array}{c}\text { after testing with organics } \\
\text { flux } \\
\left(\mathrm{mol} / \mathrm{m}^{2} \cdot \mathrm{s}\right)\end{array}$ & $\begin{array}{c}\text { salt rejection } \\
(\%)\end{array}$ & $\begin{array}{c}\text { flux } \\
\left(\mathrm{mol} / \mathrm{m}^{2} \cdot \mathrm{s}\right)\end{array}$ \\
\hline $\mathrm{CACN}$ & 95.50 & 0.1610 & 97.04 & 0.1258 \\
$\mathrm{CAHP}$ & 95.65 & 0.1941 & 96.30 & 0.1759 \\
$\mathrm{CA}$ & 96.10 & 0.3048 & 97.09 & 0.2780 \\
\hline
\end{tabular}

test conditions : $25 \pm 0.5^{\circ} \mathrm{C}, 2.0 \mathrm{MPa}, \mathrm{NaCl}: 3500 \mathrm{ppm}$

aldehydes, ethers etc. And the experimental results have been interpreted using "Preferential Sorption Capillary Flow" model. They concluded that solute separation of organics in reverse osmosis was governed by the hydrogen bonding ability of the organic molecule when it was essentially undissociated and by electrostatic repulsion of ions when the molecule was partially or compelectely dissociated. They also provided some physicochemical criteria for RO separation of organics such as $\Delta \nu_{s}$ (shift in the $\mathrm{OH}$ band maximum in the IR spectra) as well as the Taft number and Hammett number for alcohols and phenols ${ }^{1)}, \mathrm{Ka}$ (dissociation constant) and the degree of dissociation of the molecule for organic acids ${ }^{3)}$, the Small's number for hydrocarbons ${ }^{4)}$.

The distribution properties and separation properties for alcohols have been investigated using liquid chromatography and reverse osmosis before $^{6)}$. The results have been discussed according to the polarity, non-polarity, and steric effect of organic molecule. It was shown that the main factors, coming from the chemical nature of organics, governing the properties of distribution and separation were different because of the differences in the performance of solute between liquid chromatography and reverse osmosis processes ${ }^{6)}$.

Some modified CA membrane materials such as $\mathrm{CACN}^{7)}, \mathrm{CAHP}^{8}$ ), titanium cellulose acetate $(\mathrm{TiCA})^{9)}$, etc. have been synthesized with regard to CA because of its weakness and studied befrore. The resistance to microbial decomposition ${ }^{(0)}$, thermal stability ${ }^{8} .9$ ) , and antipollution ability ${ }^{11}$ ) have been improved as compared with $\mathrm{CA}$.

In this work the reverse osmosis separation of $n$-alkyl aliphatic alcohols, acids, amines and these organics with different structures in aqueous solutions have been studied using the cellulose acetate derivatives- $\mathrm{CACN}, \mathrm{CAHP}$ and $\mathrm{CA}$ membranes. The effect of operating pressure on the reverse osmosis properties has been investigated. An analysis of experimental data with SpieglerKedem's transport model has also been carried out to obtain the membrane constants such as reflection coefficient $\sigma$, solute and hydraulic permeabilities $\omega$ and $\mathrm{Lp}$.

\section{EXPERIMENTAL}

\section{1 Materials}

Cyanoethyl cellulose acetate (CACN), hydroxypropyl cellulose acetate (CAHP) and cellulose acetate were the same as reported previously ${ }^{6}$.

\section{2 Membrane Preparation}

The compositions of membrane casting solutions, the conditions and the procedures for membrane casting were all the same as reported earli$\mathrm{er}^{6)}$. All membranes were subjected to an initial permeation of pure water under pressure of 2.5 $\mathrm{MPa}$ for 2 hours, prior to their subsequent use in RO experiments.

\section{3 Reverse Osmosis (RO) Experiments}

The experimental apparatus and the procedure for $\mathrm{RO}$ experiments were as described in a previ- 


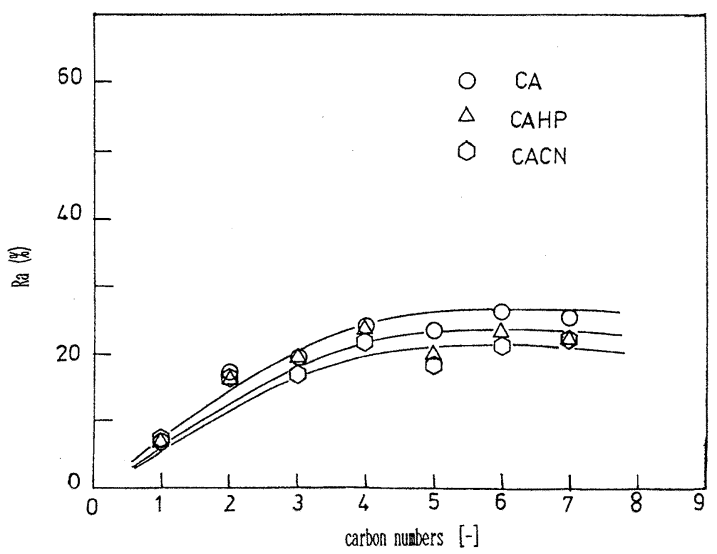

Fig. 1 The separation properties for $n$-alkyl aliphatic acids

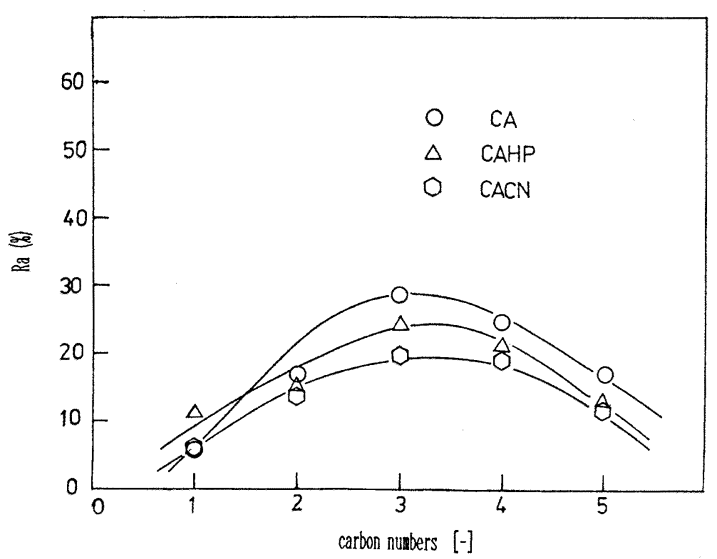

Fig. 3 The separation properties for $n$-alkyl aliphatic alcohols

ous paper ${ }^{6}$. Both before and after testing with organic solutes the membranes were subjected to a test solution of sodium chloride $3500 \mathrm{ppm}$ to re-evaluate their properties of the membranes and their constancy. The results were shown in Table 1. All membranes were tested with single-solute solution of $500 \pm 50 \mathrm{ppm}$. Each test solution was circulated over membrane surface under test conditions for 2 hours prior to collecting the permeate samples.

A Shimadzu total carbon analyzer, Model TOC500 , equipped with an automatic sample injector, ASI-502, was used to measure the concentration of

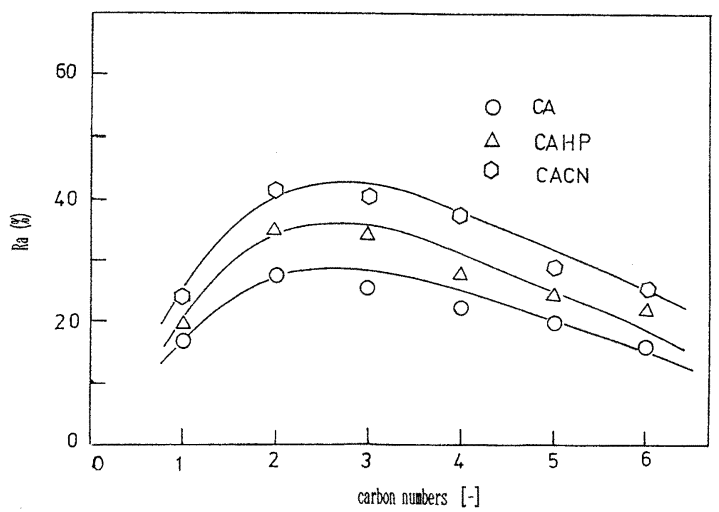

Fig. 2 The separation properties for $n$-alkyl aliphatic amines

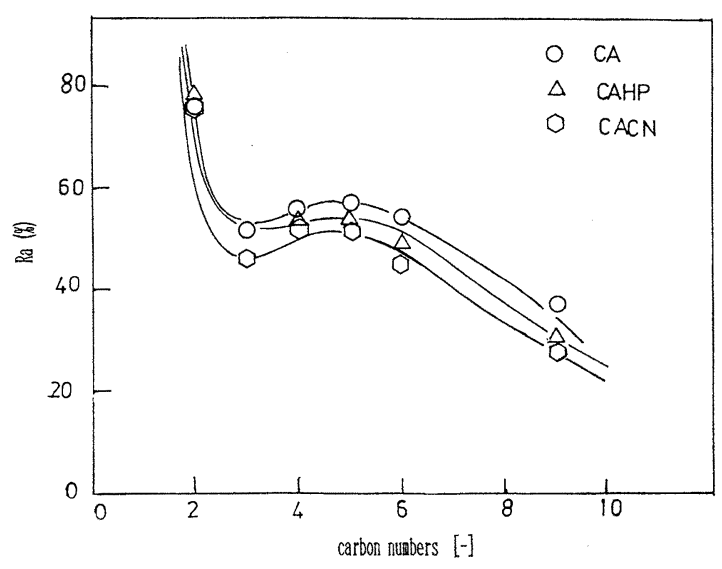

Fig. 4 The separation properties for $n$-alkyl dicarboxylic acids

organics in both permeate and feed solutions.

\section{EXPERIMENTAL RESULTS AND DISCUSSIONS}

\section{1. The Separation Properties for $n$-alkyl Or- ganics}

The separation properties of CACN, CAHP and CA membranes for $n$-alkyl aliphatic acids, amines and alcohols were shown in Fig. 1, 2, 3, respectively. It was found that at first the solute rejections increased with the carbon numbers of organics and reached a maxmium when the organic molecule contained about three carbon atoms, and then 


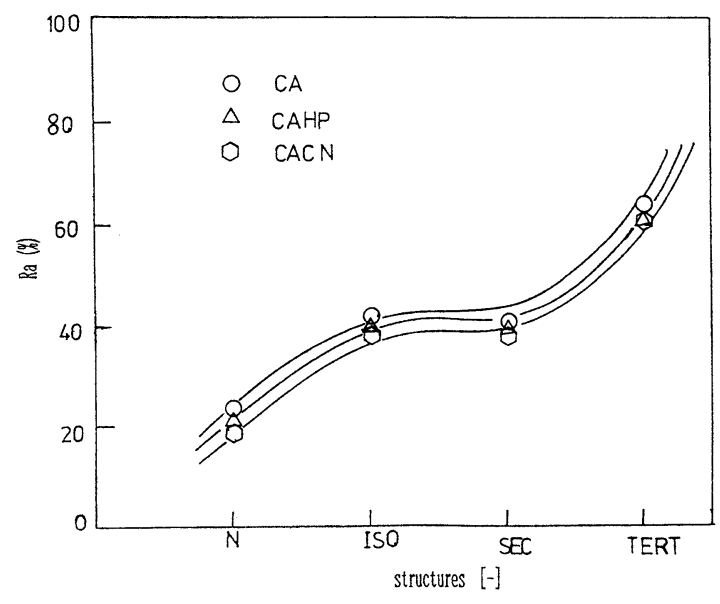

Fig. 5 The separation properties for valeric acids with different structures

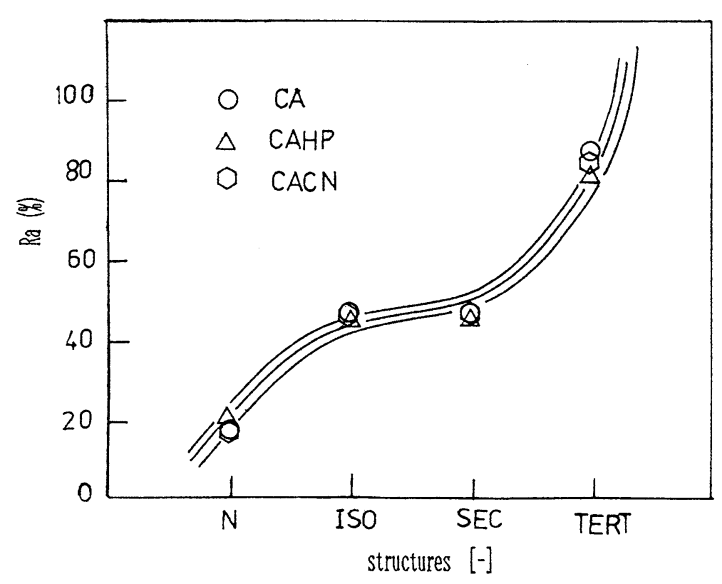

Fig. 7 The separation properties for butyl alcohols with different structures

kept constant for $n$-aliphatic acids or decreased for $n$-aliphatic amines and alcohols. This was mainly due to the increase of the distribution of solute with longer carbon chains into membrane as discussed in a previous paper for alcohols ${ }^{6)}$. The separation properties for $n$-alkyl dicarboxylic acids were also shown in Fig. 4. It could be seen that the solute rejections for dicarboxylic acids were larger than those for monocarboxylic acids, especially for oxalic acid because of the dissociation degrees.

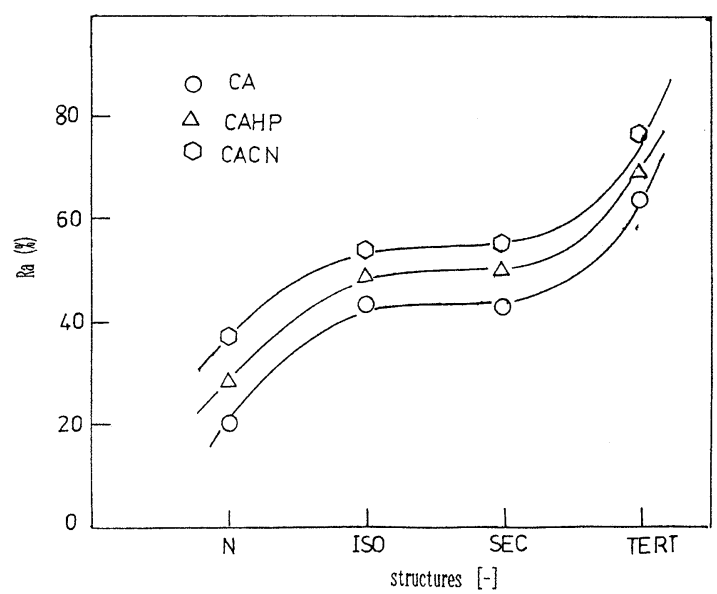

Fig. 6 The separation properties for butylamine with different structures
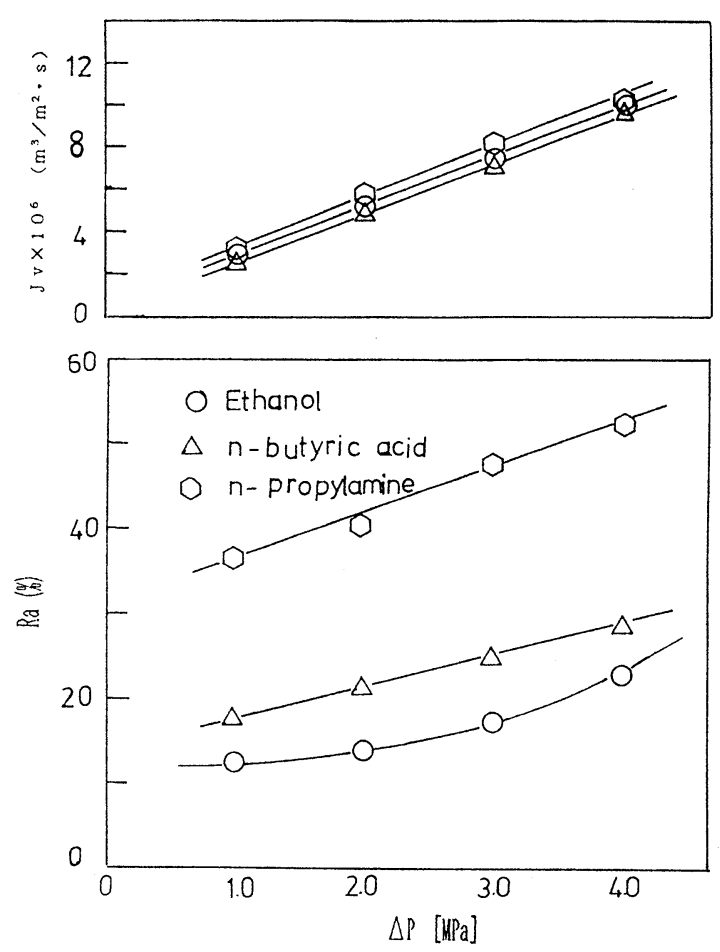

Fig. 8 The effect of operating pressure on the $\mathrm{RO}$ properties of CACN membrane

\section{2 The Separation Properties for Organics with Different Structures}

The separation properties of CACN, CAHP and CA membranes for valeric acids, butylamines and butyl alcohols with different structures were 

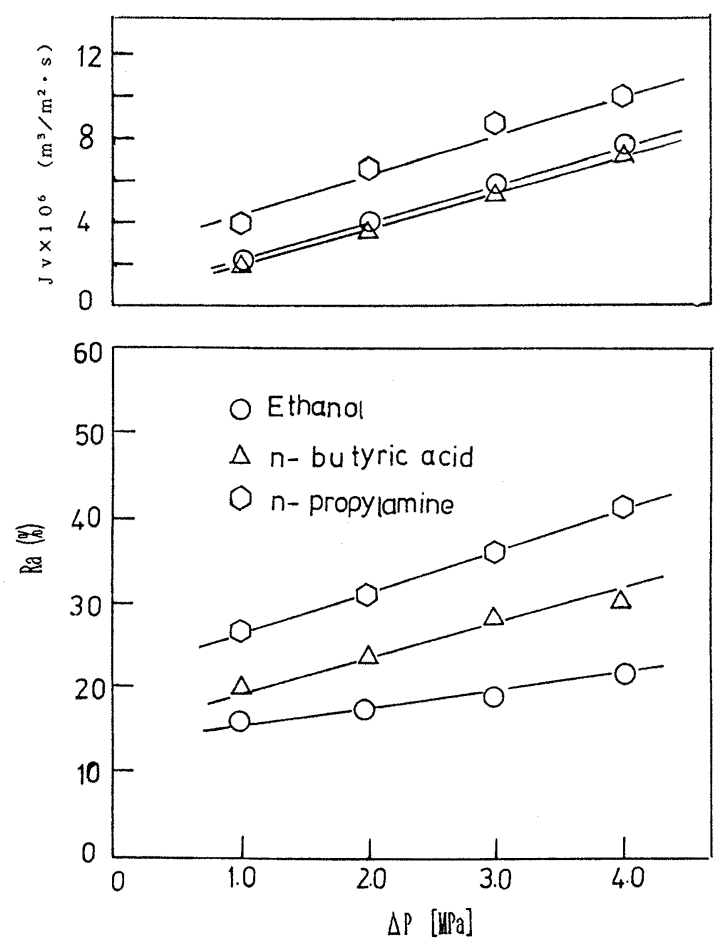

Fig. 9 The effect of operating pressure on the $\mathrm{RO}$ properties of CAHP membrane

shown in Fig. 5, 6, 7, separately. It could be seen that the solute rejections for these organics with different structures all followed the order of $n-<$ iso- $\sim$ sec- $<$ tert-. Obviously this was mainly due to the effect of steric hindrance.

\section{3 The Effect of Operating Pressure}

The effect of operating pressure on the RO properties of CACN, CAHP and CA membranes were shown in Fig. 8, 9, 10, respectively as the examples for $n$-butyric acid, $n$-propylamine and ethyl alcohol. It was found that both the solute rejections and the fluxes of solutions increased with the increase of the operating pressure in the experimental extent.
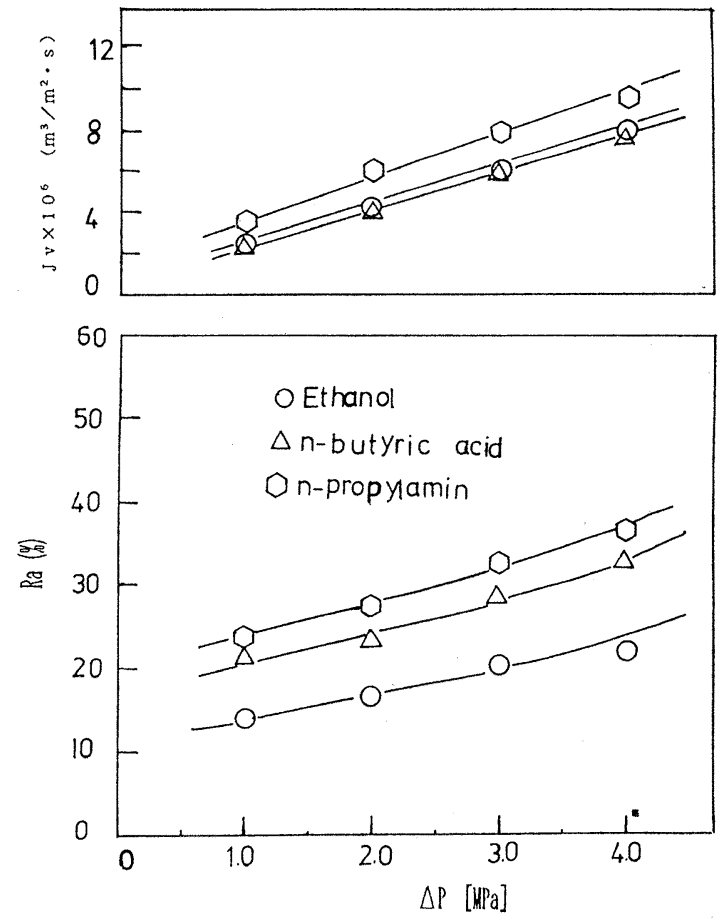

Fig. 10 The effect of operating pressure on the $\mathrm{RO}$ properties of $\mathrm{CA}$ membrane

\section{ANALYSIS OF EXPERIMENTAL DATA}

\section{1. Transport Equation}

The relation between concentration of solute at the membrane suface $\left(\mathrm{C}_{2}\right)$ and concentration in the bulk solution $\left(\mathrm{C}_{1}\right)$ can be expressed by Eq. (1) as follows ${ }^{12)}$.

$$
\left(\mathrm{C}_{2}-\mathrm{C}_{3}\right) /\left(\mathrm{C}_{1}-\mathrm{C}_{3}\right)=\exp (\mathrm{Jv} / \mathrm{k})
$$

Where $\mathrm{C}_{3}$ is the concentration of solute in the permeate solution, $\mathrm{k}$ is the mass transfor coefficient at membrane surface. In this RO system and cells used, $\mathrm{k}$ can be obtained by the following equation as reported earlier ${ }^{13}$ )

$$
\mathrm{Sh}=1.77 \mathrm{Re}^{0.734} \mathrm{Sc}^{0.33}
$$

Where $\mathrm{Sh}=\mathrm{kd} / \mathrm{D}, \mathrm{Sc}=\nu / \mathrm{D}, \mathrm{Re}=\mathrm{Ud} / \nu$. The concentration of solute at the membrane surface $\left(\mathrm{C}_{2}\right)$ can be obtained from Eq. (1).

The process of permeation of any binary solu- 
黄・大矢・根岸 : 䣷酸セルロース誘導体逆浸透膜による低分子量有機物水溶液の分離特性の研究

Table 2 Membrane Constants of CACN for Several Organic Solutes

\begin{tabular}{lccc}
\hline \multicolumn{1}{c}{ solutes } & $\begin{array}{c}\sigma \\
{[-]}\end{array}$ & $\begin{array}{c}\mathrm{Lp} \times 10^{12} \\
{\left[\mathrm{~m}^{3} / \mathrm{m}^{2} \cdot \mathrm{Pa} \cdot \mathrm{s}\right]}\end{array}$ & $\begin{array}{c}\omega \times 10^{9} \\
{\left[\mathrm{~mol} / \mathrm{m}^{2} \cdot \mathrm{Pa} \cdot \mathrm{s}\right]}\end{array}$ \\
\hline Methanol & 0.09246 & 2.7800 & 4.9889 \\
Ethanol & 0.3398 & 2.6599 & 3.7758 \\
$n$-propyl alcohol & 0.4600 & 2.7275 & 3.6201 \\
$n$-butyl alcohol & 0.2354 & 2.7713 & 1.3833 \\
$n$-amyl alcohol & 0.1418 & 2.5912 & 1.2813 \\
\hline Formic acid & 0.1752 & 2.5924 & 3.8880 \\
Acetic acid & 0.3386 & 2.5682 & 3.1481 \\
$n$-propionic acid & 0.3624 & 2.6445 & 2.9021 \\
$n$-butyric acid & 0.3931 & 2.5324 & 2.2520 \\
$n$-valeric acid & 0.2456 & 2.5825 & 1.9410 \\
\hline Methylamine & 0.6935 & 3.0701 & 4.9407 \\
Ethylamine & 0.7243 & 3.1559 & 2.2213 \\
$n$-propylamine & 0.7552 & 2.9891 & 2.3368 \\
$n$-butylamine & 0.5162 & 2.9857 & 1.4842 \\
\hline
\end{tabular}

Table 3 Membrane constants of CAHP for Several Organic Solutes

\begin{tabular}{lccc}
\multicolumn{1}{c}{ solutes } & $\begin{array}{c}\sigma \\
{[-]}\end{array}$ & $\begin{array}{c}\mathrm{Lp} \times 10^{12} \\
{\left[\mathrm{~m}^{3} / \mathrm{m}^{2} \cdot \mathrm{Pa} \cdot \mathrm{s}\right]}\end{array}$ & $\begin{array}{c}\omega \times 10^{9} \\
{\left[\mathrm{~mol} / \mathrm{m}^{2} \cdot \mathrm{Pa} \cdot \mathrm{s}\right]}\end{array}$ \\
\hline Menthanol & 0.0980 & 2.1902 & 3.0251 \\
Ethanol & 0.3431 & 2.0729 & 2.5670 \\
$n$-propyl alcohol & 0.3599 & 2.1396 & 1.3593 \\
$n$-butyl alcohol & 0.3029 & 2.1541 & 1.2952 \\
$n$-amyl alcoho] & 0.2128 & 1.9918 & 1.7618 \\
\hline Formic acid & 0.2100 & 1.9750 & 3.7123 \\
Acetic acid & 0.4060 & 1.9660 & 2.6290 \\
$n$-propionic acid & 0.3305 & 2.0320 & 1.6412 \\
$n$-butyric acid & 0.4095 & 1.9301 & 1.5576 \\
$n$-valeric acid & 0.2958 & 1.9754 & 1.2730 \\
\hline Methylamine & 0.6838 & 1.7968 & 4.2512 \\
Ethylamine & 0.6149 & 1.8062 & 2.4563 \\
$n$-propylamine & 0.5887 & 1.9761 & 1.7240 \\
$n$-butylamine & 0.3142 & 2.3796 & 1.0353 \\
\hline
\end{tabular}

tion through a membrane is described by the following Spiegler-Kedem's transport equation ${ }^{15}$ )

$$
\mathrm{Jv}_{\mathrm{v}}=\mathrm{Lp}(\Delta \mathrm{P}-\sigma \Delta \pi)
$$

$$
\mathrm{Js}=\omega \Delta \pi+(1-\sigma) \mathrm{Jv}_{\mathrm{V}} \overline{\mathrm{Cs}}
$$

Spiegler and Kedem ${ }^{15}$ ) divided the membrane into differential element in the direction of its thickness and applied Eq. ( 3 ) in it in the form of a dif- 
Table 4 Membrane Constants of CA for Several Organic Solutes

\begin{tabular}{lccc}
\hline \multicolumn{1}{c}{ solutes } & $\begin{array}{c}\sigma \\
{[-]}\end{array}$ & $\begin{array}{c}\mathrm{Lp} \times 10^{9} \\
{\left[\mathrm{~m}^{3} / \mathrm{m}^{2} \cdot \mathrm{Pa} \cdot \mathrm{s}\right]}\end{array}$ & $\begin{array}{c}\omega \times 10^{9} \\
{\left[\mathrm{~mol} / \mathrm{m}^{2} \cdot \mathrm{Pa} \cdot \mathrm{s}\right]}\end{array}$ \\
\hline Menthanol & 0.0800 & 2.2700 & 3.1256 \\
Ethanol & 0.3223 & 2.1852 & 2.1643 \\
$n$-propyl alcohol & 0.3146 & 2.3235 & 0.8212 \\
$n$-butyl alcohol & 0.3178 & 2.3330 & 1.1084 \\
$n$-amyl alcohol & 0.2258 & 2.1995 & 1.2332 \\
\hline Formic acid & 0.2387 & 2.2354 & 5.4066 \\
Acetic acid & 0.4212 & 2.1816 & 3.0665 \\
$n$-propionic acid & 0.4193 & 2.2264 & 2.5862 \\
$n$-butyric acid & 0.3111 & 2.0829 & 1.0885 \\
$n$-valeric acid & 0.3111 & 2.3227 & 1.2796 \\
\hline Methylamine & 0.5971 & 2.3738 & 5.2272 \\
Ethylamine & 0.6146 & 3.0581 & 3.4639 \\
$n$-propylamine & 0.5254 & 3.4279 & 3.0717 \\
$n$-butylamine & 0.2054 & 3.8970 & 1.4975 \\
\hline
\end{tabular}

ferential equation, integrating the equation to give the following intrinsic rejection $\left(R_{i n t}\right)$.

$$
\mathrm{R}_{\text {int }}=1-\mathrm{SP}=\left(\mathrm{C}_{2}-\mathrm{C}_{3}\right) / \mathrm{C}_{2}=\sigma(1-\mathrm{F}) /(1-\sigma \mathrm{F})
$$

where

$$
\mathrm{F}=\exp \left[-(1-\sigma) \mathrm{Jv}_{\mathrm{v}} /(\omega \mathrm{RT})\right]
$$

By extrapolating $\mathrm{Jv}$ to infinite value, the value of $\mathrm{R}_{i n t}$ in Eq. (5) approches reflection coefficient $\sigma$ as the value of $\mathrm{F}$ approches zero.

\section{2 Estimation of $\sigma, L p$ and $\omega$}

As mentioned above, the reflection coefficient $\sigma$ can be obtained by extrapolating the intrinsic rejection $R_{i n t}$ to infinite flux $\mathrm{Jv}$ or zero of $1 / \mathrm{Jv}$ on the ordinate axis. Therefore, we can plot $\mathrm{R}_{i n t} \mathrm{v}$. s. $1 / \mathrm{Jv}$ and get the reflection coefficient $\sigma$ by extrapolating $R_{i_{n}}$ to zero of $1 / \mathrm{Jv}$ as described earlier ${ }^{15)}$.

By using $\sigma$ estimated as above, the hydraulic and solute permeabilities Lp, $\omega$ can be obtained from Eq. (3) and (4) where $\overline{\mathrm{Cs}}$ is the logarithmic averaged molar concentration of $\mathrm{C}_{2}$ and $\mathrm{C}_{3}$, and $\Delta \pi$, the osmotic pressure was estimated using the van't Hoff equation as follows

$$
\Delta \pi=\mathrm{RT} \Delta \mathrm{C}
$$

\section{3. Analysis Results and Discussions}

The values of $\sigma, \mathrm{Lp}$, and $\omega$ obtained by the method as mentioned above, for several organic solutes were shown in Table 2, 3, and 4, for CACN, CAHP and $\mathrm{CA}$ membranes respectively. It could be seen that the hydraulic permeability almost unchanged with the carbon number of organic molecules having the same functional group, while the solute permeability decreased with the increase of the carbon numbers because of the steric hindrance.

\section{CONCLUSIONS}

1. Cellulose acetate derivatives-cyanoethyl cellulose acetate, hydroxypropyl cellulose acetate and cellulose acetate membranes have been prepared and the reverse osmosis separation of low molecular weight organics have been investigated. It was found that the solute rejections of $n$-alkyl aliphat- 


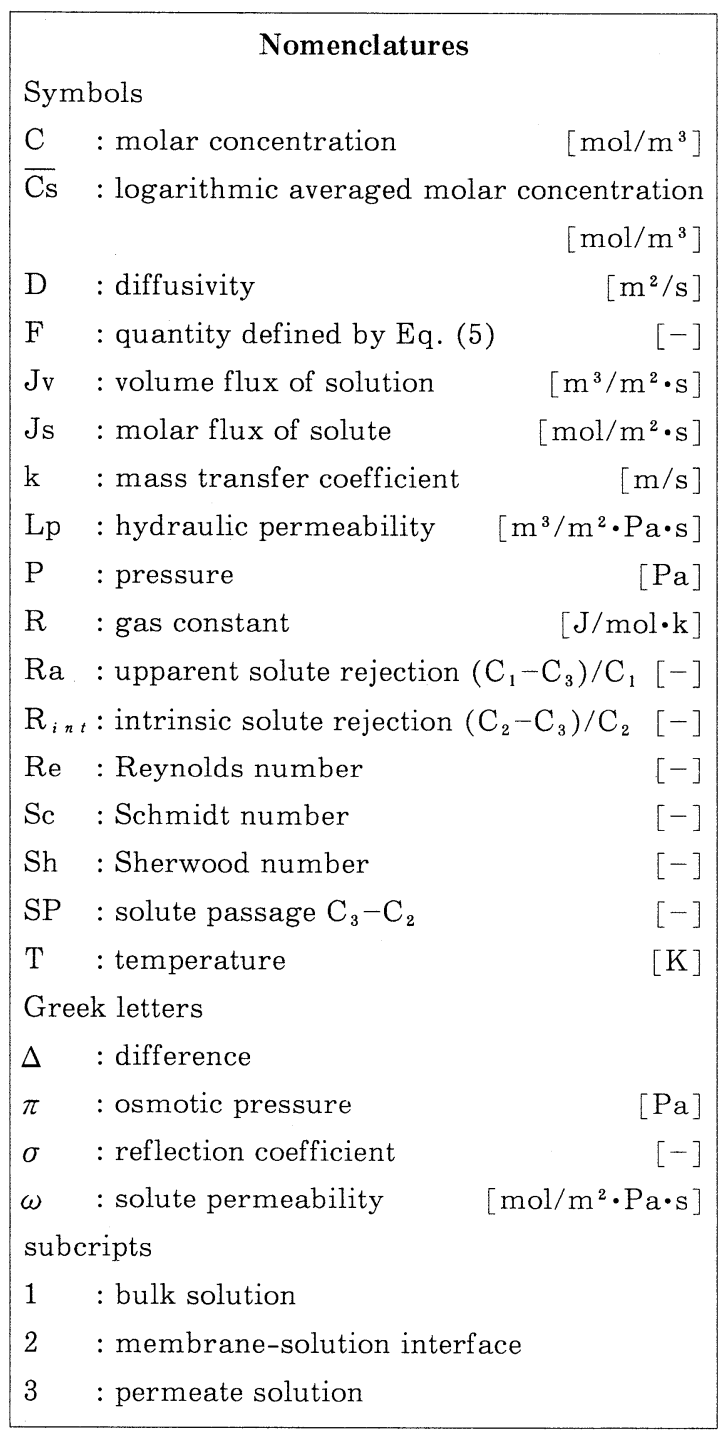

ic acids, amines, and alcohols atfirst increased with the increase of carbon numbers and reached a maximum when the organic molecule contained about three carbon atoms, and then kept constant or decreased. The order of solute rejections for organics with different structures was $n-<$ isosec- $<$ tert- because of the steric hindrance.

2. Both the solute rejections and the solution fluxes increased with the increase of operating pressure.

3. An analysis of experimental data with Spiegler-Kedem's transport model has been carried out and some membrane constants such as reflection coefficient $\sigma$, solute and hydraulic permeabilities $\omega$ and Lp have been obtained for several organic solutes. It was found that the hydraulic permeability Lp almost unchanged with the carbon numbers of the organics having the same functional group, while the solute permeability $\omega$ decreased with the increase of the carbon numbers because of the steric effects coming from the molecular size.

Acknowledgement

One of the author, Huang Jicai, wants to appreciate Showa Denko Co. Ltd. for offering him accommodation when he studied in Japan.

\section{REFERENCES}

1) T. Matsuura and S. Sourirajan : J. Appl. Polym. Sci., 15, 2905 (1971)

2) T. Matsuura and S. Sourirajan : J. Appl. Polym. Sci., 17, 1043 (1973)

3) T. Matsuura and S. Sourirajan : J. Appl. Polym. Sci., 17, 3661 (1973)

4) T. Matsuura and S. Sourirajan : J. Appl. Polym. Sci., 17, 3683 (1973)

5) T. Matsuura and S. Sourirajan : J. Appl. Polym. Sci., 16, 1663 (1972)

6) H. Ohya, Huang Jicai and Y. Negishi : Membrane, 18 (1), 11 (1993)

7) Chen Liankai, Qi Qinghui and Guo Yanfang : Technology of Water Treatment (special edition) 11, 11 (1985)

8) Huang Jicai, Mao Runsheng and Wu Fenglian : Chinese Journal of Applied Chemistry, 8 (4), 34 (1991)

9) Huang Jicai, Wu Fenglican, Qi Qinghui and Mao Runsheng: Water Treatment, 5, 414 (1990)

10) Qi Qinghui, Chen Liankai and Guo Yanfang : Cell. Chem. Technol., 21, 359 (1987)

11) Liu Tinghui : Documents of International Summer School on Membrane Science and Technology, No. 10, Natong, China (1988)

12) S. Kimura and S. Sourirajan : AlChE J., 13, 497 (1967)

13) K. S. Spiegler and O. Kedam : Desalination, 1, 311 (1966)

14) H. Ohya, M. Okada and Y. Negishi : Rep. Asahi Glass Found. Ind. Technol., 45, 217 (1984)

15) H. Ohya, Zhou Jianhui, T. Hara, T. Hino, Y. Negishi : Membrane, 14 (6), 407 (1989) （受付 1993 年 2 月 25 日） 